\title{
Perícias em saúde e Saúde do Trabalhador: a definição do tempo de afastamento em foco
}

\author{
Health Evaluation and Worker's Health: \\ the definition of the length of medical leave in focus
}

Vivian Heringer Pizzinga (https://orcid.org/0000-0003-4602-2267) ${ }^{1}$

Rafaela Teixeira Zorzanelli (https://orcid.org/0000-0001-7531-8492) ${ }^{1}$

${ }^{1}$ Instituto de Medicina Social Hesio Cordeiro, Universidade do Estado do Rio de Janeiro. R. São Francisco Xavier 524, Maracanã. 20550-013 Rio de Janeiro RJ Brasil. vivianhp@globo.com

\begin{abstract}
For the purpose of analyzing topics linking the health-disease-work process to medical evaluation practices under the scope of the federal public service and their interaction with Worker's Health, this article investigates the issue of determining the duration of the sick leave period that a worker is granted for caring for their own health, within the Subsistema Integrado de Atenção à Saúde do Servidor (SIASS). To that end, the parameters for granting time off work, as provided by the Manual de Perícia Oficial, and the speeches on this topic by the interviewees were analyzed. The importance given to the topic 'days off work' arises from the fact that it is related to the time it takes the worker to recover, which implies fewer days dedicated to being productive. Interviews were conducted with 32 professionals from 5 educational institutions, and this article highlights some analytical categories: days off work; Manual da Perícia and disagreement between medical evaluators and attending physicians. The results point to the usefulness of revising the Manual taking into account Worker's Health, identifying contradictions; the need for shaping an effectively interdisciplinary evaluation, so that the worker's health-related complaints can be handled from the perspective of the worker's care, and not simply concerning control and surveillance.
\end{abstract}

Key words Worker's Health, Health evaluation, Federal public service
Resumo No intuito de analisar temas que ligam as questões dos processos de saúde-doença-trabatho às práticas periciais no serviço público federal e seu diálogo com a Saúde do Trabalhador, este artigo se debruça sobre o tema da definição do tempo para tratamento da própria saúde, na esfera do Subsistema Integrado de Atenção à Saúde do Servidor Público (SIASS). Para isso, examinaram-se os parâmetros de afastamento fornecidos pelo Manual de Perícia Oficial e as falas sobre esse tópico por parte dos entrevistados. A importância conferida ao tema se deve ao fato de estar associado ao tempo de recuperação do trabalhador, o que implica menos dias destinados à produtividade. Entrevistaram-se 32 profissionais de 5 instituições de ensino, enfatizando-se, neste artigo, as categorias analíticas que conduziram aos pontos explorados: dias de afastamento, Manual de Perícia e divergências entre profissionais da perícia e médicos assistentes. Os resultados indicam a utilidade de revisar o Manual com base na Saúde do Trabalhador, identificando contradições; a necessidade de construção de uma perícia efetivamente interdisciplinar; e que a queixa dos periciados possa ser manejada da perspectiva do cuidado ao trabalhador, e não apenas com referência no controle e na vigilância.

Palavras-chave Saúde do Trabalhador, Perícia em saúde, Serviço público federal 


\section{Introdução}

O paradigma da Saúde do Trabalhador tem como objetivo nortear intervenções nos processos saúde-doença no trabalho, e seus pressupostos constituem os princípios de atuação no Subsistema Integrado de Atenção à Saúde do Servidor Público Federal (SIASS), que, desde 2009, quando substituiu o sistema anterior (Sistema Integrado de Saúde Ocupacional do Servidor Público Federal - SISOSP) anterior centrado no paradigma da saúde ocupacional, opera ações de atenção à saúde do servidor público federal no Poder Executivo. Tendo o campo da Saúde do Trabalhador como ideal para pensar os processos saúde-doença no trabalho, este artigo apresenta os achados sobre o momento decisório dos peritos acerca do tempo de afastamento (dias de licença) para tratamento da própria saúde nas perícias em saúde realizadas em unidades SIASS. A noção de tratamento da própria saúde é diferente daquele que se refere ao acompanhamento de familiar em tratamento de saúde e sem autonomia, cujo tempo implica um prazo máximo bastante inferior ao tratamento da própria saúde, denotando a importância do tempo nas decisões periciais. Os achados se originam em entrevistas semiestruturadas e em profundidade, realizadas ao longo de 2019, com profissionais de perícia de 5 instituições federais do estado do Rio de Janeiro. Dentro desse tema, analisaremos, a partir das falas dos profissionais entrevistados, o papel do Manual de Perícia do SIASS e as divergências dos peritos em relação aos laudos trazidos por outros médicos que acompanham os trabalhadores periciados, os chamados médicos assistentes. Investigando critérios da seção do Manual de Perícia sobre a concessão do tempo de licença, analisamos o modo como esse prazo é avaliado pelo perito e equipe de saúde, e qual a margem de negociação entre a posição do perito e as demandas expressas pelo trabalhador. Essa proposta se originou de tese de doutorado defendida em 2020, cujo objetivo era, em síntese, investigar a função das perícias em saúde no SIASS a partir da visão de seus praticantes.

Quantos aos princípios da Saúde do Trabalhador evocados pelo SIASS, Machado', com base em análise de textos normativos desse sistema, observa a falta de certa coesão conceitual no que concerne à adoção dos pilares do campo. Os princípios teóricos que aparecem nos textos normativos muitas vezes mostram-se híbridos e se confundem com o viés teórico da Saúde Ocupacional, que considera a multicausalidade na produção da doença, mas os riscos ou agente etiológicos são descontextualizados, não sendo levadas em conta, por outro lado, as relações sociais e institucionais no adoecimento no trabalho. Essa confusão teórica, presente em algumas diretrizes do SIASS, mostra-se problemática na medida em que suas ações se estendem por uma vasta população de servidores públicos federais e, deste modo, requerer um quantitativo de profissionais de saúde igualmente vasto, cujas abordagens podem ser as mais heterogêneas possíveis, no sentido negativo que essa heterogeneidade pode adquirir na prática da atenção à saúde do servidor (mescla de atuações influenciadas pelos três paradigmas ligados ao adoecimento no trabalho, quais sejam: a medicina do trabalho, a saúde ocupacional e a Saúde do Trabalhador). Para se ter a dimensão da magnitude do SIASS, cabe apontar que deve abranger um total de 1.051 .580 (um milhão e cinquenta e um mil e quinhentos e oitenta) servidores federais civis e militares ativos em todo o país ${ }^{2}$, de acordo com dados do Ministério da Saúde.

Sublinha-se que o estabelecimento dos princípios da Saúde do Trabalhador no âmbito do serviço público federal ainda precisa de muitos desenvolvimentos ${ }^{3,4}$, dado que alguns de seus princípios encontram dificuldades para serem efetuados, sendo sua vinculação com o SUS e as políticas de saúde ainda precária, ocupando uma posição mais marginal face às ações efetivas dessa área ${ }^{5}$. Por outro lado, Lacaz ${ }^{5}$ identificava, em 2007, um retrocesso no campo da Saúde do Trabalhador, verificado em função de três aspectos: a fragilidade que já acometia o movimento sindical, a atitude de escasso engajamento da academia e a políticas públicas reducionistas, ligadas à Saúde Ocupacional' ${ }^{6}$.

Cabe ainda lembrar que, como apontam Minayo-Gomez e Thedim-Costa ${ }^{7}$, a Saúde do Trabalhador é "uma meta, um horizonte" e requer um "agir político, jurídico e técnico", além de um "posicionamento ético". A Saúde do Trabalhador incorpora princípios do Modelo Operário Italiano (MOI), segundo o qual a reforma sanitária deveria permitir o reconhecimento de que a doença, para além de um sofrimento pessoal, é "o sinal de um conflito histórico entre homem, natureza e sociedade". Assim, se esses princípios indicam um horizonte a ser buscado, serve-nos, nesta pesquisa, como ideal a partir do qual se analisam os dados oriundos das falas dos entrevistados no que tange ao seu entendimento sobre os dias de afastamento para tratamento da própria doença, por parte dos trabalhadores, $\mathrm{e}$ 
às negociações acerca das decisões periciais que envolvem a temática.

\section{Método}

As perícias em saúde do SIASS são realizadas em instituições federais por médicos e odontólogos peritos que emitem laudos técnicos com decisões periciais acerca dos pleitos de saúde dos servidores. Nem todas as instituições federais possuem unidades SIASS, havendo acordos de cooperação técnica para a realização das perícias em saúde. É central destacar que a noção de perícia em saúde se distancia, em teoria, da de perícia médica, uma vez que pressupõe um trabalho pericial que conjugue diferentes saberes técnicos. Assim, o SIASS prevê a existência da chamada equipe de suporte à perícia, composta por profissionais como psicólogos e assistentes sociais, que dão suporte à decisão do médico. Para o estudo que originou este artigo, foram realizadas 32 entrevistas semiestruturadas, com médicos (20), odontólogos (3), psicólogos (4), assistentes sociais (4) e fisioterapeuta (1), selecionados a partir de contatos prévios das pesquisadoras e do método bola de neve. As entrevistas foram analisadas com auxílio do software de pesquisa qualitativa, o Atlas.ti, que auxilia a organização de categorias obtidas nas entrevistas. O roteiro buscou guiar-se por questões referentes à concepção dos entrevistados quanto ao papel da perícia em saúde no serviço público federal, sua formação acadêmica e experiência profissional, como sanam suas dúvidas (surgindo aí o protagonismo do Manual de Perícia do SIASS), a diferença de seu trabalho quando ocorre no cenário da perícia e quando se dá no cenário assistencial e, por fim, a forma como o trabalho em equipe acontece (quando existe). Um dos achados das entrevistas foi a frequência com que surge a discussão sobre o tempo de licença.

A importância conferida à temática da decisão pericial sobre os dias de afastamento permite iluminar, ao menos, dois pontos: 1) interesses priorizados ou não no processo de perícia, já que quanto mais dias o servidor estiver em processo de recuperação, menos dias estará disponível para o trabalho e, 2) em que medida a perspectiva do trabalhador é levada em conta nesse processo de decisão ou não. Neste artigo, analisaremos o tema específico dos "dias de afastamento" partir de como o tema apareceu na análise de entrevistas de profissionais do SIASS.

\section{Tempo de afastamento do trabalho: um ângulo de análise}

A questão referente ao tempo de afastamento pode parecer uma questão menor, no entanto, trata-se de pensar o tempo do trabalhador dedicado a si, ao seu restabelecimento, e não ao trabalho. Em outras palavras, trata-se do que é objeto central na discussão sobre o trabalho: o tempo. Sobre isso, Foucault afirma: "É preciso que o tempo dos homens seja oferecido ao aparelho de produção; que o aparelho de produção possa usar o tempo de vida, o tempo de existência dos homens. É para isto e desta forma que o controle se exerce" ". A citação permite lembrar que a questão dos dias de afastamento pode deixar de se vincular à saúde propriamente dita para se ligar à produtividade.

A relevância da discussão sobre o tempo de afastamento - ou dias de licença - reside na relação entre tempo, trabalho e capitalismo. No modo de produção capitalista, o controle sobre o tempo que o trabalhador dedica a trabalhar e, portanto, à produção - constitui o cerne do trabalho nesse tipo de sistema. A mais-valia, segundo Marx, é precisamente extraída do tempo que não se paga ao sobre trabalho, como recorda Braverman ${ }^{10}$. Desse modo, cabe lembrar que as mudanças macrossociais, sobretudo as que aconteceram a partir da década de 1970, com mais uma crise estrutural do capitalismo, geraram transformações que impactaram a forma de se pensar tanto o trabalho quanto o tempo ${ }^{11,12}$. Também neste sentido, Crary ${ }^{13}$ analisa a questão do tempo que se extrai da vida dos sujeitos para que sirvam aos sistemas de trabalho e ao consumo inerentes à lógica capitalista. Ao apontar pesquisas do governo estadunidense sobre o comportamento de pássaros que não descansam ao longo de uma trajetória de dias, o autor evidencia o objetivo de compreender esse fenômeno biológico que permite longas vigílias sem prejuízo de rendimento, para sua posterior reprodução em seres humanos. A ideia seria chegar àquilo que o autor chama de "trabalhador sem sono", que se torna, ao fim e ao cabo, o "consumidor sem sono", no que seria um evidente processo de colonização irrestrita do tempo do sujeito. Pode-se deduzir que a pausa (o sono diário, o descanso e também os dias de licença) impede a contínua produtividade.

A questão do tempo de trabalho é tão central que o regramento jurídico em relação à aposentadoria por invalidez, por exemplo, de acordo com a Lei $\mathrm{n}^{\circ}$ 8.112, que traz as normas 
do Regime Jurídico Único em âmbito federal, em seu artigo 188, estabelece que tal modalidade de aposentadoria "será precedida por licença para tratamento de saúde por período não excedente a 24 (...) meses"14. Já o tempo de serviço, fundamental para fins previdenciários, também situa $\mathrm{o}$ tempo dedicado ao trabalho como requisito para a obtenção de direitos sociais e, de acordo com cada ordenamento, incluirá ou não alguns tipos de afastamento, todos muito bem especificados.

O debate sobre o tempo é essencial ainda em termos de gerenciamento do comportamento laboral dentro de uma dada instituição, e assim parece ser desde o advento da chamada Administração Científica (ou taylorismo), em que os gestos dos trabalhadores deveriam ser maquinais para que coubessem no tempo medido (eram calculados em minúcia para fins de produtividade e otimização, revertidas em ganhos do capitalista $)^{15}$. Uma vez mais, a discussão é relevante na medida em que talvez os tempos do capital não sejam os mesmos que os necessários aos processos de saúde/doença. Segundo Canguilhem, "estar em boa saúde é poder cair doente e se recuperar"16. Logo, a possibilidade de adoecer compõe o estado de saúde, e adoecer exige recuperar-se, o que demanda um prazo que não pode ser abreviado. Essa recuperação está também atrelada à discussão de Berardi ${ }^{17} \mathrm{em}$ torno da impossibilidade de expansão do que nomeia de cibertempo, cujos limites se referem à intensidade da experiência vivida. Logo, a experiência de adoecimento (a intensidade que lhe é intrínseca sendo um de seus elementos) é singular, e não se esgota em tabelas fixas. A recuperação de um adoecimento - a saúde, conforme Canguilhem - seria, segundo o que se pode inferir da contribuição de Berardi, o momento necessário de reserva, assimilação e processamento das experiências vividas.

A questão dos dias de afastamento nas discussões acerca da perícia em saúde traz à cena o debate sobre absenteísmo e seu desenvolvimento conceitual mais específico, o par absenteísmo-doença, de acordo com nomenclatura da Organização Internacional do Trabalho. Estudo realizado em serviços públicos do município de Goiânia reforça aspectos relacionados às condições de trabalho, deduzidos a partir de indicadores do absenteísmo-doença. A pesquisa aponta que sua análise, quando associada ao perfil dos afastamentos, pode gerar não apenas informações sobre as condições de saúde dos trabalhadores, como sobre as condições de trabalho em que se inserem ${ }^{18}$. Os resultados do estudo indicam uma prevalência maior de dias de afastamento para tratar a própria saúde relacionada, nessa ordem, aos transtornos mentais, às doenças osteomusculares e a lesões. Conforme se acenará à frente, a quantidade de dias de afastamento face a diagnósticos psiquiátricos geram divergências entre médicos peritos e assistentes.

Segundo Santi et al. ${ }^{19}$, há uma relação entre absenteísmo-doença e a continuidade de atividades essenciais para os cidadãos no que tange ao serviço público, o que traria ônus aos cofres públicos devido à não-produtividade e às despesas com a reabilitação do trabalhador. As autoras assinalam um ponto central que nos indica o que a negociação sobre o tempo de licença revela: os dias de afastamento são compreendidos como absenteísmo para o erário público. A noção de absenteísmo avulsa, sem sua contraparte relativa à doença, parece estar imbuída de conotação negativa devido ao ônus que geraria. Entretanto, consideramos aqui que, da perspectiva da saúde do trabalhador, dias de afastamento, ainda que sejam mais numerosos do que os indicados no Manual de Perícia, podem ser o tempo necessário para a recuperação de sua saúde.

\section{Resultados}

Os resultados a seguir concentram-se nos temas que se relacionaram diretamente com o tópico do tempo de afastamento a partir das entrevistas, ou seja, como são trazidos, pelos profissionais ouvidos, os critérios que guiam as decisões quanto à concessão dos dias de licença (quantidade, renovação ou não do prazo de afastamento, convergência ou discordância do que é indicado nos laudos dos médicos assistentes), como esse prazo é avaliado pelo perito e por demais profissionais de saúde e, por fim, qual a margem de negociação entre sua posição e as demandas do trabalhador periciado. Dividimos, assim, em três pontos centrais: Manual da Perícia, já que este é o instrumento regulatório que oferece orientações sobre o tempo de licença; Dias de afastamento, que aponta a forma como ideias e valores são levados em conta pelo perito em seu processo decisório; Divergência do Médico Assistente, para analisar como a figura do médico assistente aparece nas entrevistas.

\section{Manual da Perícia}

A perícia é o momento em que o servidor terá sua demanda de saúde avaliada por profissionais que têm o poder, fazendo uso de algum 
argumento legal, de satisfazê-la ou negá-la. Se o servidor adoece, é ali que ele terá deferido ou não seu afastamento e a definição do tempo necessário para se recuperar, e é ali que poderá ser aposentado por invalidez. Esses são apenas alguns exemplos dos tipos de avaliação que chegam à perícia, tratando-se de um momento às vezes decisivo na vida do trabalhador. Em nossa análise, percebemos que há vários aspectos emaranhados nas concepções sobre a prática de perícia de seus profissionais, somados às que compõem o texto do Manual de Perícia, mas, para facilitar a argumentação, podemos isolar dois aspectos principais, sabendo que as variáveis que se imiscuem nesse processo são inúmeras. Assim, o julgamento sobre os dias de licença de um servidor se entrelaça com a desconfiança que o Manual incita o perito a ter em relação aos servidores em geral.

Segundo o Manual, existe uma diferença entre o médico que trata de um paciente e o médico cuja função é periciar. A descrição dessas duas relações as situa em dois extremos, como se não houvesse, entre eles, uma série de possibilidades de interação. A relação entre médico que trata e seu paciente pressuporia confiança e interesse do paciente em contar tudo sobre sua doença ao médico, levando-o à honestidade total. Já na relação médico perito e periciado, existiria mútua desconfiança. Nesse caso, o interesse do servidor em obter algum tipo de benefício poderia levá-lo à simulação e, portanto, a uma expectativa apriorística de fraude por parte dos profissionais de perícia, o que os situa em um lugar bem distante da isenção que é reivindicada pelo texto do Manual e em algumas falas dos entrevistados. Além da confiança, a "empatia" seria algo presente apenas na relação de tratamento, e não na relação pericial. Há, no texto, um constante reforço de que o perito deve tomar cuidado com a possibilidade de simulação, devendo ele "defender a Administração Pública Federal”, viés que pode afastar o trabalhador dos direitos sociais previstos constitucionalmente, igualando a todos de antemão, como se os servidores periciados estivessem, em sua maioria, em busca de ganhos secundários (ilegítimos) que devem ser detectados pelos peritos. Essas e outras formas de definir as relações periciais acabam por situar esse tipo de prática em uma esfera de conflito. Não há menção, na mesma frequência, à relação do adoecimento com a organização de trabalho no Manual de Perícia.

A suspeita em relação aos relatos do periciado pode trazer grande sofrimento aos servidores cujas doenças não são reconhecidas ou não se encaixam no dispositivo legal. Nos casos daquilo que Dumit ${ }^{20}$ chama de "doenças que você deve lutar para ter" (illnesses you have to fight to get), isto é, doenças que são caracterizadas por incerteza quanto ao diagnóstico, ao tratamento e ao prognóstico e que não possuem marcadores biológicos que atestem sua legitimidade, a possível descrição predominante do periciado como alguém de quem se deve desconfiar de antemão é algo ainda mais problemático. Essas pessoas têm de lutar para ter um diagnóstico no sentido de que possuem o sofrimento e os sintomas, mas não são reconhecidas em seu adoecimento pelo fato de que não há uma nomeação para aquilo que apresentam ou, mesmo que haja, é repleta de incertezas por ser uma doença emergente

Com a justificativa de conferir "transparência aos atos de avaliação"21, o Manual traz uma tabela de afastamentos correspondentes aos vários diagnósticos. Para citar exemplos dos Transtornos Mentais, orienta-se 20 dias para episódio depressivo e transtornos fóbicos e ansiosos, 30 para esquizofrenia e transtorno obsessivo-compulsivo e 7 para transtornos somatoformes, transtornos dissociativos ou conversivos. Mas há outras correspondências, como 3 dias para torcicolo, 2 para gastrite, 15 para glaucoma, entre outros. O que se percebe é que o máximo de tempo de afastamento concedido a qualquer dos diagnósticos de saúde mental é de 30 dias. Esses parâmetros de tempo de afastamento levantam diversas questões que acabam por se relacionar também à expectativa de fraude.

Uma das principais questões que aparece no processo decisório em torno do tempo de afastamento é a discordância entre o perito e o laudo do médico assistente. Quando o servidor chega à perícia com um laudo de seu médico assistente indicando um número de dias maior do que o perito considera razoável, tem-se aí um problema. O perito, conforme mencionado em algumas entrevistas, o que se verá na próxima seção, tende a discordar do médico assistente, buscando reduzir o tempo de licença, mas indaga-se: com base em que o perito julga que uma dada quantidade de dias de licença é excessiva? Nos casos de saúde mental e de sofrimentos que se vinculam à organização do trabalho, por exemplo, mesmo que não se estabeleça o nexo causal, o diagnóstico é uma ficção. Ou uma ilusão de objetividade, de homogeneidade. Afinal, diante de um mesmo nome - depressão, transtorno de ansiedade generalizada - uma miríade de reações pode surgir, cujo tempo de recuperação é impossível de se prever. Um episódio depressivo pode ter a ver 
com uma perseguição vivida no ambiente laboral, com a falta de sentido referente ao desvio de função, com reestruturações na esfera institucional. Tudo isso leva ao mesmo número de dias de afastamento?

No que tange às entrevistas, não parece haver um questionamento por parte do perito quanto ao motivo pelo qual o médico assistente pode ter se decidido a dar 'mais' dias do que o suposto razoável. O que terá o trabalhador dito a ele que não terá encontrado ambiente de "confiança mútua” na perícia para relatar? O que o médico assistente sabe que o perito talvez não saiba? Não é possível ter conhecimento dessas questões sem que haja uma escuta e a busca daquilo que, no trabalho, nas relações institucionais, pode estar ou não atrelado àquele adoecimento. A primazia da suspeita do servidor faz com que o perito possa cair em um hábito de suspeitar de tudo, inclusive do médico assistente.

Conforme mencionado, as entrevistas levaram à constituição de diversos eixos analíticos, e em relação ao Manual de Perícia, apenas médicos (20) e assistentes sociais (1) se referiram a ele. Algumas dessas menções misturam-se àquelas referidas ao tempo de licença. Há diversas citações ao referido Manual como fonte de consulta diante de dúvidas. Como há ausência de formação para o trabalho com perícia na experiência da maioria dos médicos entrevistados (de 20 médicos, apenas 1 apresentava formação aproximada da perícia), o Manual também assume a função de formação e é por isso que é tão importante, tendo uma influência significativa sobre os profissionais:

[...] eu cheguei já entrando nessa função... fui ler o manual, lógico que eu não absorvi toda a informação, então eu fui ler o manual em casa pra eu entender e eu tive a sorte de ter aqui uma pessoa que já tinha a experiência, [...] então até hoje eu tiro dúvida com ela, porque a gente não teve curso de formação, eu acho que isso é uma coisa deveria ter havido [...] (médica 4).

Outras vezes ele é citado como uma espécie de "prova dos nove" na ausência de termo melhor. É o que se vê abaixo:

[...] às vezes a gente tem que ir lá no manual pra relembrar se condiz o que a pessoal tá dizendo e tudo (médica 2).

O que salta aos olhos no trecho acima é o fato de que o Manual ganha precedência sobre o relato da experiência trazido pelo servidor. Ele é usado como um guia da verdade, por assim dizer, em que serão cotejadas as falas do trabalhador e as indicações ali registradas.
O Manual também é citado como uma espécie de fonte da etiqueta pericial: os ritos periciais, as formas de proceder, o receituário da interação no momento da perícia, tudo está lá. Uma das características da relação entre o perito e o periciado deve ser a isenção e o distanciamento, conforme examinamos ao falar sobre a ausência da empatia na descrição dessa relação. O texto do Manual é uma justificativa desse tipo de comportamento:

No próprio manual do SIASS tem lá a definição do médico perito, como ele deve se portar, a gente tem que manter uma certa distância (médica 5).

Finalmente, há também menções mais questionadoras das regras de conduta que o Manual oferece, como se vê abaixo:

Mandar e-mail, e aí "nossa, pode ver esse caso", "liga pro servidor", "nossa, ligou pra mim", não quero saber o que está acontecendo... E isso burla o manual. Até o manual de saúde a gente acaba burlando. Se a rigor, a rigor, a gente não poderia fazer nada disso, mas quando a gente faz e vê que $o$ resultado é muito bom pro servidor, isso vale... nossa... não tem preço... (médico 6).

No exemplo acima, o perito vinha descrevendo a forma como ele age com os servidores, nada distanciada ou formal e, neste sentido, aponta a transgressão que faz àquilo que o texto do SIASS sugere, identificando essa transgressão como seu papel social, no sentido de oferecer um bom acompanhamento ao trabalhador, tratá-lo com dignidade, preocupar-se com ele.

\section{Dias de Afastamento}

Em relação à temática dos dias de afastamento, da forma como o perito lida com o Manual e da divergência que pode ocorrer com o que recomenda o médico do servidor, alguns trechos são ilustrativos da discussão levantada na seção anterior:

[...] muitas das vezes, a gente pensa que o médico assistente deu dias demais de afastamento. Não sei, porque o olhar dele não é o olhar nosso, o olhar dele é assim "olha, ele não tem capacidade de trabalhar provavelmente por tantos dias", ele acaba colocando um pouquinho a mais, eu sou assistencialista, a gente tende a fazer isso e a gente tende a atender... a vontade do paciente... mas no processo pericial esse julgamento desses dias, dependendo do tipo de trabalho, [...] você pode ter alternativas, de um retorno gradual, tem várias opções, aí vem a legislação nossa, né, e essa gradação é que é o gostoso, a meu ver, e é o diferencial (médica 1).

Por acaso, essa médica, ao longo da entrevista, traz algumas falas em que identifica o traba- 
lho do perito como aquele que poderá buscar a vinculação do adoecimento com os processos de trabalho. Há, nas descrições que fornece, aproximações com as noções cruciais da Saúde do Trabalhador, tornando a perícia em saúde conciliável com esse campo. Entretanto, aqui, há julgamento apriorístico do médico assistente, que vira essa figura abstrata que se encaixa em todos os casos.

Outro exemplo mostra a mesma questão, atrelada à ideia de um poder decisório que cabe ao perito, à assimetria da relação entre ele e os outros personagens da perícia, seja o servidor, seja o médico assistente:

[...] chega atestado de 3 meses, chega atestado de tempo indeterminado, não existe isso, cabe o perito fazer essa avaliação, assim como ele pode diminuir o tempo, pode aumentar, cabe ao perito porque a palavra final é do perito, né [...] (médica 2).

Nesse exemplo, parece que, em toda a questão, o que de fato importa é a "palavra final", que pertence ao médico perito. Não há nenhuma outra argumentação face às decisões de aumentar ou diminuir os dias.

Abaixo, reproduzimos um trecho que une duas unidades de sentido: dias de afastamento e Manual de Perícia:

[...] as [doenças] mais comuns a gente tem uma estimativa média que eles orientam pra dar de licença, então, vamos supor, depressão... é lógico que aquilo ali é uma média e a gente tem que avaliar caso a caso, mas, por exemplo, depressão ele orienta 30 dias, então, assim, já teve casos de pessoas que chegaram aqui com atestado de 90 dias pra depressão, então a gente pode, pra não se indispor também, mostrar a orientação do próprio Manual que é de 30 dias, podendo ser renovada, mas o próprio Manual, pras doenças mais prevalentes, ele te dá um guia pra você poder se orientar e tentar seguir aquilo ali, mas é claro que isso é muito relativo, já dei 60 dias, mas tem casos que eu dei trinta... então aquilo é meio que um guia pra gente (médica 3 ).

Há um trecho de um dos profissionais de odontologia em que o tempo de licença é questionado, mas sem que se enquadre o servidor ou a improcedência de seu pleito em uma situação de malícia. Percebe-se a motivação de sofrimento que pode estar por trás desse tipo de queixa, o que, a nosso ver, concilia a perícia em saúde com os princípios da Saúde do Trabalhador:

Mas eu tenho recebido casos que tem me causado [...] e eventualmente a pessoa vem pra perícia e começa a contar história que perpassa pelo assédio, pela necessidade de se afastar do ambiente de trabalho, como se ela tivesse procurado todas as possibilidades e aî "eu vou meter um atestado odontoló- gico". [...] E começo a perceber que as pessoas têm começado a se articular mais [risos] para conseguir esse tipo de afastamento. E eu converso muito com as pessoas, quando é possivel logicamente, se houver necessidade, eu amplio até o prazo de recuperação do paciente, não necessariamente eu sou obrigada a aceitar o que o atestado... se o atestado dá 3 dias e eu acho que a pessoa precisa de 7 dias, eu vou dar 7 dias pra pessoa [...] (odontóloga 2).

A odontóloga reconhece as situações em que o atestado é utilizado de modo deliberadamente incorreto, porém a forma com que lida com isso, a interpretação que atribuía esse gesto, permite pensar mais amplamente naquilo que o trabalho vem promovendo, em termos de sofrimento e vontade de se ausentar.

Abaixo, outro trecho mostra o exemplo da depressão, citado por outra médica, no mesmo sentido já usado antes: 90 dias parece muito, uma vez que é o triplo daquilo que o Manual orienta:

Mas [...] se é uma dúvida assim, "ah, sei lá, eu tô achando que é muito tempo de licença", aí uma das opções que às vezes eu uso é usar o próprio manual do SIASS, até pra explicar pra pessoa, sei lá, a orientação são 30 dias e o médico tá pedindo 90, eu mostro, "olha, em geral é esse valor, eu vou dar esses 30 dias, mas se precisar renovar o senhor pega um laudo mais detalhado com seu médico, pra explicar por que que precisa de mais tempo", [...] em geral não tem problema, as pessoas entendem bem, assim, que existem alguns períodos sugeridos que a gente tem que mais ou menos cumprir (médica 4).

Esse é outro exemplo que une as unidades de sentido do Manual de Perícia e dos dias de afastamento, sendo que o Manual adquire a função de recurso ao qual o perito se apoiará para evitar beligerância. O argumento utilizado, no entanto, é o de que os "períodos sugeridos" devem ser "mais ou menos" cumpridos pelo perito, alçando os parâmetros à categoria de lei, o que não é verdade, possuindo caráter apenas discricionário.

Uma das psicólogas entrevistadas fala sobre a diminuição do tempo por parte do médico e das discussões que se dão em torno disso:

[...] às vezes eles [os peritos] tentam homologar por menos tempo e eu sugiro mais, ou já falaram da aposentadoria por invalidez, eu falo "poxa, acho que ainda não, acho que a gente ainda tem que dar uma chance", e elas ouvem [...] (psicóloga 1).

Se pudermos pensar que um dos desafios da Saúde do Trabalhador é conseguir operacionalizar seus princípios também no campo das perícias, indicaríamos que a prática pericial deveria se preocupar, antes de tudo, com a relação entre adoecimento/sofrimento e trabalho e, assim, a 
questão do tempo de afastamento talvez fosse percebida e avaliada de modo diferente no contexto pericial.

\section{Divergência do Médico Assistente}

Quanto à divergência do médico assistente, esta também é uma unidade de sentido ligada aos dias de afastamento, pois, em geral, as menções que aparecem, por parte do médico (14), referem-se a isso. Entre os demais profissionais, apenas psicólogos fizeram menção a essa categoria (4). Abaixo, trazemos a fala de um psicólogo que reproduz o discurso arraigado sobre a intenção do trabalhador querer ter um benefício, apesar de, em sua entrevista, fazer referências à Saúde do Trabalhador, assim como ao nexo causal:

E aí [...] A gente vê claramente que tem atestados que chegam, assim, enviesados... que o médico assistente ou outro profissional assistente, o psicólogo assistente, etc, escreveram coisas ali que estão muito distantes da realidade que você tá observando, assim, né... e é claramente assim... porque como a perícia vai fazer parte da possibilidade de obtenção de um benefício, né, você tem a pessoa que pode ficar interessada de fato de ficar mais tempo afastada e você tem o contrário também, a pessoa que tá muito adoentada e que não quer se afastar... porque vai ser malvista pelos colegas, por tudo, então [...] não é fácil isso... não é tão objetivo... (psicólogo 2).

Algumas falas relativas à "divergência com o médico assistente" já foram reproduzidas nas seções precedentes, mas ainda se pode trazer um último trecho, em que a médica refere-se a uma espécie de conluio entre servidor e médico, ou à ingenuidade desta último:

Mas é porque a gente sente que às vezes a coisa tá solta e quer verificar se realmente é aquela queixa mesmo, se tem alguma coisa importante acontecendo ali ou se foi só um atestado de combinação entre o médico... se ele exagerou pro médico assistente e não é aquilo tudo... (médica 7).

Levando-se em consideração o caso dos diagnósticos em saúde mental e os parâmetros fornecidos pelo Manual, indaga-se o quanto tais parâmetros foram preparados para acompanhar transformações em manuais classificatórios de doenças, tais quais a Classificação Internacional das Doenças (CID), que anuncia sua $11^{\text {a }}$ edição para 2022. Consideramos aqui que um parâmetro quanto aos intervalos de afastamento pode ser importante se servir de ponto de partida em casos de moléstias que os peritos não veem com frequência ou que não fazem parte do campo de conhecimento próprio de sua especialização prévia.
Se usado com parcimônia, pode ter utilidade. No entanto, esse recurso às vezes pode ganhar protagonismo nas decisões periciais, deixando de ser uma orientação para se tornar uma regra, como se o que divergisse, para mais (em termos de prazo para tratamento e recuperação da saúde), do que está especificado fosse um excesso. Os diagnósticos e os entendimentos sobre adoecimentos se transformam e uma tabela com períodos de afastamento fixa o que é mutável, cristaliza o que é dinâmico, torna geral o que é particular.

\section{Considerações finais}

A análise de parte do material empírico obtido junto a profissionais que atuam com perícia em saúde no SIASS e o exame de dado aspecto do Manual de Perícia indicou-nos que o estabelecimento do tempo de afastamento do servidor para cuidar da saúde era guiado pelo suposto de que quanto menos dias afastado do trabalho, melhor seria, da perspectiva da instituição. A decisão quanto à duração do afastamento se orientava, ainda, por uma atitude de suspeita face às queixas dos periciados. Não houve, na mesma medi$\mathrm{da}$, menções às situações nocivas do trabalho por parte dos entrevistados. O que se observou foi uma preocupação com intervalos de afastamento tidos como superiores ao razoável, sem haver problematização do que seria ou não razoável. Essas posições, sobretudo em seu efeito sinérgico, distanciam-se dos princípios da saúde do trabalhador, ainda que estes estejam indicados como valores a serem mantidos no SIASS.

Assim, conforme se apontou, o tempo necessário para a recuperação de um adoecimento, incluído no conceito de saúde que nos orienta Canguilhem $^{16}$, acaba por ser categorizado como absenteísmo e entendido como ônus aos cofres públicos, já que implicaria, segundo entendimento da gestão, pausa na produtividade. No entanto, esse prazo de afastamento das atividades laborais seria necessário ao restabelecimento das capacidades do servidor.

Acreditamos que um dos desafios da saúde do trabalhador, ao menos no âmbito do serviço público federal, é tornar mais coerente a prática dos profissionais de saúde com as diretrizes desse campo, fazendo prevalecer os aspectos relacionados à saúde em contexto de trabalho a partir de uma visão crítica. Isso talvez signifique debater e, num segundo momento, revisar o Manual de Perícias a partir da saúde do trabalhador, identificando contradições. 
Por outro lado, acrescenta-se que, no que se refere à perícia em saúde, se levamos em conta que a saúde do trabalhador como "horizonte", um trabalho efetivamente interdisciplinar se faz necessário. O Manual, não obstante oriente para que haja uma composição interdisciplinar nas perícias $^{21}$, deixa transparecer uma ênfase medicalocêntrica ao sublinhar a soberania do médico perito na decisão do pleito de saúde. Neste sentido, observamos, a partir dos dados obtidos, casos de saúde mental em que a perícia era composta por médicos de especialidades distantes da saúde mental, sem a presença de psicólogos. Essa questão faz diferença na medida em que, ainda que os profissionais não-médicos deem seus pareceres, se houver discordância, são os médicos peritos que terão proeminência, mesmo que se originem de áreas distantes da saúde mental, e a opinião de um nefrologista terá mais peso do que a de um psicólogo, por hipótese. Se uma perícia em saúde não conta com especialistas da área, a proposta de um trabalho interdisciplinar, necessário para que se estabeleça a Saúde do Trabalhador em qualquer instituição, não se efetua, com prejuízo para o trabalhador, uma vez que se pode chegar a uma avaliação imprópria quanto ao tempo de afastamento de suas atividades laborais.

Finalmente, há uma vinculação estreita entre o discurso do Manual e o dos entrevistados, no que se refere à desconfiança. A escuta dos peritos, em geral, tende a caminhar ao lado da descrição ofertada, pelo Manual, de que a suspeita deve ser o guia maior da compreensão das demandas. $\mathrm{O}$ tempo de afastamento avaliado pelos profissionais é um exemplo ilustrativo dos valores que estão em jogo na prática da perícia e que pendulam mais para a manutenção da ordem produtiva do que, de fato, para o estado vital do trabalhador. Ofusca-se, neste sentido, o sofrimento que o trabalho pode gerar e joga-se luz nos aspectos imaginários referentes à suposta trapaça que o trabalhador está prestes a fazer.

\section{Colaboradores}

VH Pizzinga e RT Zorzanelli participaram da concepção e delineamento do projeto de pesquisa e análise e interpretação dos dados, redação e revisão do artigo. A primeira autora realizou a coleta dos dados e a concepção do manuscrito inicial, sendo o artigo uma versão de parte de sua tese de doutorado em Saúde Coletiva (área de concentração Ciências Humanas e Saúde), defendida em 20 de março de 2020, no Instituto de Medicina Social da UERJ, e a segunda autora professora orientadora do referido trabalho. 


\section{Referências}

1. Machado JP. Saúde do servidor público federal: política, discursos e práticas prescritas. In: Coutinho MS, Furtado O, Raitz TR. Psicologia Social e Trabalho: perspectivas críticas. Florianópolis: ABRAPSO Editora, Edições do Bosque CFH/UFSC; 2015. p. 64-91.

2. Portal da Transparência [Internet]. [acessado 2019 out 31]. Disponível em: http://portaldatransparencia. gov.br/servidores.

3. Minayo-Gomez C. Campo de Saúde do Trabalhador: Trajetória, configuração e transformações. In: Minayo-Gomes C, Machado JMH, Pena PGL. Saúde do Trabalhador na Sociedade Brasileira Contemporânea. Rio de Janeiro: Editora Fiocruz; 2011.p. 23-34.

4. Athayde M. Saúde 'Mental' e Trabalho: questões para discussão no campo da saúde do trabalhador. In: Minayo-Gomes C, Machado JMH, Pena PGL. Saúde do Trabalhador na Sociedade Brasileira Contemporânea. Rio de Janeiro: Editora Fiocruz; 2011. p. 345-366.

5. Lacaz F. O campo Saúde do Trabalhador: resgatando conhecimentos e práticas sobre as relações trabalhosaúde. Cad Saude Publica 2007; 23(4):757-766.

6. Santos APL, Lacaz FAC. Saúde do Trabalhador no SUS: contexto, estratégias e desafios. In: Minayo-Gomes C, Machado JMH, Pena PGL. Saúde do Trabalhador na Sociedade Brasileira Contemporânea. Rio de Janeiro: Editora Fiocruz; 2011.p. 87-106.

7. Minayo-Gomez C, Thedim-Costa SMF. A construção do campo de saúde do trabalhador: percurso e dilemas. Cad Saude Publica 1997; 13(Supl. 2):21-32.

8. Berlinger G. A saúde nas fábricas. São Paulo: CEBES/ HUCITEC; 1983.

9. Foucault M. A verdade e as formas jurídicas. Rio de Janeiro: NAU Editora; 2003.

10. Braverman H. Trabalho e Capital Monopolista. A degradação do trabalho no século XX. Rio de Janeiro: Zahar Editores; 1977.

11. Harvey D. 17 contradições e o fim do capitalismo. São Paulo: Boitempo; 2016.

12. Boltansky L, Chiapello E. O novo espírito do capitalismo. São Paulo: Martins Fontes; 2009.

13. Crary J. 24/7. Capitalismo tardio e os fins do sono. São Paulo: Cosac Naify; 2014.

14. Brasil. Lei no 8.112, de 11 de dezembro de 1990. Dispõe sobre o regime jurídico dos servidores públicos civis da União, das autarquias e das fundações públicas federais. Diário Oficial da União; 1990.
15. Alves G. Trabalho e subjetividade: o espírito do toyotismo na era do capitalismo manipulaório. São Paulo: Boitempo; 2011.

16. Canguilhem G. O normal e o patológico. Rio de Janeiro: Forense Universitária; 1978.

17. Berardi F. Depois do futuro. São Paulo: Ubu Editora; 2019.

18. Leão ALM, Barbosa-Branco A, Rassi Neto E, Ribeiro CAN, Turchi MD. Absenteísmo-doença no serviço público municipal de Goiânia. Rev Bra Epidemiol 2015; 18(1):262-277.

19. Santi DB, Barbieri AR, Cheade MFM. Absenteísmodoença no serviço público brasileiro: uma revisão integrativa da literatura. Rev Bras Med Trab 2018; 16(1):1.

20. Dumit J. Illnesses you have to fight to get: facts as forces in uncertain, emergente illnesses. Soc Sci Med 2006;62(3):577-590.

21. Brasil. Ministério do Planejamento, Desenvolvimento e Gestão (MPDG). Manual de perícia oficial em saúde do servidor público federal. $3^{a}$ ed. Brasília: MP; 2017.

Artigo apresentado em 10/03/2020

Aprovado em 27/07/2021

Versão final apresentada em 29/07/2021

Editores-chefes: Romeu Gomes, Antônio Augusto Moura da Silva 